Matthias Schröder, Olga Arlt, Helmut Schmidta , Andrea Huwiler, Carlo Angioni, Josef M. Pfeilschifter, Anja Schwiebs* and Heinfried H. Radeke

\title{
Subcellular distribution of FTY720 and FTY720- phosphate in immune cells - another aspect of Fingolimod action relevant for therapeutic application
}

\begin{abstract}
FTY720 (Fingolimod; Gilenya ${ }^{\circledR}$ ) is an immunemodulatory prodrug which, after intracellular phosphorylation by sphingosine kinase 2 (SphK2) and export, mimics effects of the endogenous lipid mediator sphingosine-1-phosphate. Fingolimod has been introduced to treat relapsing-remitting multiple sclerosis. However, little has been published about the immune cell membrane penetration and subcellular distribution of FTY720 and FTY720-P. Thus, we applied a newly established LC-MS/MS method to analyze the subcellular distribution of FTY720 and FTY720-P in subcellular compartments of spleen cells of wild type, SphK1- and SphK2-deficient mice. These studies demonstrated that, when normalized to the original cell volume and calculated on molar basis, FTY720 and FTY720-P dramatically accumulated several hundredfold within immune cells reaching micromolar concentrations. The amount and distribution of FTY720 was differentially affected by SphK1- and SphK2-deficiency. On the background of recently described relevant intracellular FTY720 effects in the nanomolar range and the prolonged application in multiple sclerosis, this data showing a substantial intracellular accumulation of FTY720, has to be considered for benefit/risk ratio estimates.
\end{abstract}

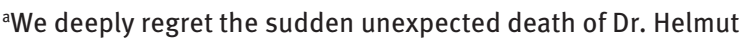
Schmidt during the preparation of the manuscript for this article. *Corresponding author: Anja Schwiebs, Pharmazentrum frankfurt/ ZAFES, Institute of General Pharmacology and Toxicology, Goethe University Frankfurt, Building 75, Theodor-Stern-Kai 7, D-60590 Frankfurt/Main, Germany, e-mail: schwiebs@em.uni-frankfurt.de Matthias Schröder: BioMed X Innovation Center, Im Neuenheimer Feld 583, 69120 Heidelberg, Germany

Olga Arlt, Josef $M$. Pfeilschifter and Heinfried H. Radeke: Pharmazentrum frankfurt/ZAFES, Institute of General Pharmacology and Toxicology, Goethe University Frankfurt, Building 75, TheodorStern-Kai 7, D-60590 Frankfurt/Main, Germany Helmut Schmidt and Carlo Angioni: Pharmazentrum frankfurt/ ZAFES, Institute of Clinical Pharmacology, Goethe University, D-60590 Frankfurt/Main, Germany

Andrea Huwiler: Institute of Pharmacology, University of Bern, $\mathrm{CH}-3012$ Bern, Switzerland
}

Keywords: lymphocytes; mass-spectrometry; multiple sclerosis; sphingosine kinase; sphingosine 1-phosphate; subcellular compartment.

DOI 10.1515/hsz-2014-0287

Received December 1, 2014; accepted January 9, 2015; previously published online January 14, 2015

\section{Introduction}

FTY720 (2-amino-2-[2-(4-octylphenyl)ethyl]-propane1,3-diol, Fingolimod, Gilenya $\left.{ }^{\circledR}\right)$ is an immune-modulatory prodrug derived from the natural compound myriocin, which is produced by the fungus Isaria sinclairii. It is phosphorylated intracellularly by sphingosine kinase 2 but not sphingosine kinase 1, producing FTY720-phosphate (FTY720-P) (Paugh et al., 2003). FTY720-P acts as a functional analog of the endogenous ligand sphingosine1-phosphate (S1P), which has pleiotropic effects in angiogenesis (Limaye, 2008), neurological excitability (Bryan et al., 2008), cell differentiation (Moriue et al., 2008; Saddoughi et al. 2008; Qin et al., 2010) and inflammation (Huwiler and Pfeilschifter, 2008; Spiegel and Milstien, 2011). Therefore, in its phosphorylated state, FTY720 has been proposed to interfere with functions mediated by S1P and is thus investigated in basic research. Moreover, it is approved for the treatment of lymphocyte-driven multiple sclerosis in men. In order to function via cognate receptors, both amphiphilic compounds, S1P and FTY720-P, have to leave the cell by an energy-dependent process mediated by transporters. Several partly conflicting reports have been published regarding the S1P transport mediated by $\mathrm{ABC}$ transporters, such as ABCA1, ABCC1 and ABCG2 (Liu et al., 2014; Nishi et al., 2014) as well as for the spinster homolog 2 (SPNS2) (Hisano et al., 2011; Fukuhara et al., 2012).

Outside the cell S1P can bind to five distinct G-protein-coupled receptors and - dependent on the 
expression profiles of these five S1PRs - elicits cell-typespecific responses (Blaho and Hla, 2014). FTY720-P exhibits nanomolar affinities for all of these apart from $\mathrm{S}_{\mathrm{PP}}$ (Mandala et al., 2002). Upon binding of S1P or FTY720-P the receptors internalise. This internalisation is prolonged upon FTY720-P-binding compared to S1P-binding because the receptors are not readily recycled but ubiquitindependently degraded inside the cell to a greater extent, reducing the total number of receptors being recycled (Brinkmann et al., 2010; Oo et al., 2011). Thus, besides its agonistic action FTY720 is also a partial functional antagonist of S1P. As S1PR is essential for the trafficking of immune cells such as T and B cells, dendritic cells and macrophages from lymphatic organs into the bloodstream, the functional antagonistic property of FTY720-P causes their sequestration and ultimately interferes with the migration of these cells to sites of inflammation (Matloubian et al., 2004; Schwab et al., 2005, Cinamon et al., 2008). This mechanism is exploited by the recently approved FTY720-treatment of multiple sclerosis, which supposedly traps autoreactive $\mathrm{T}$ cells inside the lymph nodes (Brinkmann et al., 2010). For the long-term application of FTY720 during the treatment it is important to reliably measure the concentrations of FTY720 and FTY720-P in human plasma and especially in the subcellular compartments of the target cells. Although the in vivo metabolism of FTY720 and the extracellular effect of FTY720-P on $\mathrm{S}_{1} \mathrm{P}_{1,35}$ are well understood (Brinkmann et al., 2010; Oo et al., 2011), far less is known about its distribution at subcellular levels.

In the present study we investigated several aspects of cellular handling and metabolism of FTY720 in vitro, using LC-MS/MS to quantify FTY720 and FTY720-P. We determined the overall intracellular accumulation and the subcellular localization of FTY720 and FTY720-P in major compartments, and whether this distribution is affected by the lack of either SphK1 or SphK2. As might be expected from a pharmacological judgement of the Fingolimod structure, our data clearly stress the fact that this prodrug significantly accumulates inside immune cells. Thereby we are directing more attention to recently described relevant intracellular targets such as S1P-metabolizing enzymes or phospholipases that might contribute to additional effects of the compound in disease treatment.

\section{Results}

To determine how FTY720 and FTY720-P are distributed in different cellular compartments of spleen cells and how this distribution is affected by the deletion of sphingosine kinases, we used wt-C57BL/6, SphK1- and SphK2-deficient spleen cells and incubated them with $1 \mu \mathrm{M}$ FTY720 for $15 \mathrm{~h}$. We determined FTY720 and FTY720-P in the supernatant, cytosol, membrane and nuclear fractions, which have been separated as stated in the Methods section. Our investigations revealed, that the distribution of FTY720 and FTY720-P was different among the four fractions and was, interestingly, not only dependent on the presence of SphK2 but also on SphK1. In our first approach determining the drug concentrations in the respective cellular compartment preparations, independent from the intracellular and extracellular volume as well as the suspension volume, we measured FTY720 amounts highest in the nuclear fraction of wild type cells $(54.63 \pm 25.70 \mathrm{ng} / \mathrm{ml})$ (Table $1 \mathrm{~A})$. FTY720-P was mainly detected in the supernatant $(55.77 \pm 33.57 \mathrm{ng} / \mathrm{ml})$ and the cytosol $(54.59 \pm 24.70 \mathrm{ng} / \mathrm{ml})$. Different from wild type cells, in SphK1-deficient splenocytes we measured both FTY720 (129.64 $\pm 13.58 \mathrm{ng} / \mathrm{ml})$ and FTY720-P (127.75 $\pm 5.87 \mathrm{ng} / \mathrm{ml})$ at highest levels in the cytosol (Table 1B). Cells deficient for SphK2 were unable to phosphorylate FTY720 and generate FTY720-P, which consequently led to higher amounts of FTY720 in the supernatant $(75.71 \pm 28.27 \mathrm{ng} / \mathrm{ml})$ and the cytosol $(172.23 \pm 42.99$ $\mathrm{ng} / \mathrm{ml}$ ) (Table 1C). We also normalized the amounts of the drugs to the extracellular volume (supernatant) or the suspension volume (subcellular compartments) in order to provide total amounts (Table 1). Furthermore, to illustrate physiologically relevant concentrations of both drugs, in Figure 1 we show levels of FTY720 and FTY720-P normalized to their respective molecular weights. Notably, this calculation offered that FTY720 was mainly localized in the supernatant from wild type and SphK1-deficient cells (Figure 1). Interestingly, the same was true for FTY720-P which has been transported out of the cells upon phosphorylation. However, FTY720-P was not found in the supernatant of SpK2-deficient cells, as FTY720 could not be phosphorylated in those cells. Notably, we thus found higher extracellular levels of the parental compound.

Nevertheless, Table 1 and Figure 1 imply the overall determined compartment distribution of FTY720 and of FTY720-P based on the absolute quantities of the compounds determined by LC-MS/MS, normalized to the volume of supernatant and volume of cell suspension obtained by applying the lipid extraction method and the final volumes for the measurement. To obtain the actual situation present in a united cells structure, we estimated the exact amounts of FTY720 and FTY720-P by evaluating the volume of a single cell compared to its extracellular space (Figure 2). To calculate the extra- and intracellular fractions we confirmed the mean splenocyte volume by an intensive literature study. In agreement with our own 
Table 1 Extra- and intracellular distribution of FTY720 and FTY720-P in murine splenocytes.

\begin{tabular}{|c|c|c|c|c|c|}
\hline & Fractions & FTY720 (ng/ml) & FTY720 (ng) & FTY720-P (ng/ml) & FTY720-P (ng) \\
\hline \multicolumn{6}{|l|}{$A$} \\
\hline \multirow[t]{4}{*}{ WT } & Supernatant & $24.53 \pm 8.76$ & $122.63 \pm 43.78$ & $55.77 \pm 33.57$ & $278.83 \pm 167.86$ \\
\hline & Cytosol & $21.17 \pm 26.50$ & $10.59 \pm 13.25$ & $54.59 \pm 24.70$ & $27.30 \pm 12.35$ \\
\hline & Membrane & $31.53 \pm 16.53$ & $12.61 \pm 6.61$ & $11.96 \pm 8.45$ & $4.79 \pm 3.38$ \\
\hline & Nucleus & $54.63 \pm 25.70$ & $43.71 \pm 20.56$ & $20.19 \pm 13.73$ & $16.15 \pm 10.98$ \\
\hline \multicolumn{6}{|l|}{$B$} \\
\hline \multirow[t]{4}{*}{ SphK1-/- } & Supernatant & $19.42 \pm 2.73$ & $97.09 \pm 13.64$ & $67.96 \pm 7.19$ & $339.79 \pm 35.93$ \\
\hline & Cytosol & $129.64 \pm 13.58$ & $64.82 \pm 6.79$ & $127.75 \pm 5.87$ & $63.88 \pm 2.94$ \\
\hline & Membrane & $2.58 \pm 0.63$ & $1.03 \pm 0.252$ & $3.26 \pm 0.68$ & $1.30 \pm 0.27$ \\
\hline & Nucleus & $20.23 \pm 3.85$ & $16.18 \pm 3.08$ & $9.66 \pm 2.01$ & $7.73 \pm 1.60$ \\
\hline \multicolumn{6}{|c|}{ 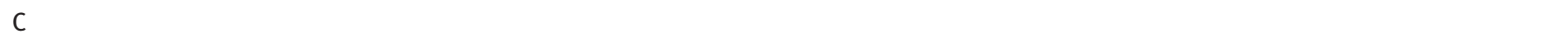 } \\
\hline \multirow[t]{4}{*}{ SphK2-/- } & Supernatant & $75.71 \pm 28.27$ & $378.56 \pm 141.36$ & 0 & 0 \\
\hline & Cytosol & $172.23 \pm 42.99$ & $86.11 \pm 21.49$ & 0 & 0 \\
\hline & Membrane & $23.32 \pm 14.70$ & $9.33 \pm 5.88$ & 0 & 0 \\
\hline & Nucleus & $38.35 \pm 13.45$ & $30.68 \pm 10.76$ & 0 & 0 \\
\hline
\end{tabular}

The obtained FTY720/FTY720-P concentrations from LC-MS/MS measurement are given in $\mathrm{ng} / \mathrm{ml}$ and in $\mathrm{ng}$, calculated on the basis of the volume used for the lipid extraction procedure, for (A) wt-C57BL/6, (B) SphK1 $\%$ and (C) SphK2 $\%$ spleen cells. For each measurement, $20 \times 10^{6}$ splenocytes were incubated for $15 \mathrm{~h}$ with $1 \mu \mathrm{M}$ FTY720 and the amount of FTY720 and FTY720-P was quantified with LC-MS/MS. Data are given as mean \pm SD from six independent experiments. For statistical analysis two-way ANOVA was used.

measurements (data not shown), many reliable investigations measured a median mouse lymphocyte diameter close to $7 \mu \mathrm{m}$, which equals a volume of spheric cells of $180 \mathrm{fl}$ (von Andrian and Mackay 2000; Rathmell et al., 2001). Lymphocytes comprise the main population in the spleen, as erythrocytes are lysed in our cell culture proto$\mathrm{col}$, leading to a determination of a volume of $3.6 \mu \mathrm{l}$ as the total cellular volume for all $20 \times 10^{6}$ splenocytes. Notably, these calculations offered a completely new insight into the real distribution of the compounds. As shown in Figure 2, FTY720 and FTY720-P accumulated dramatically inside the cells compared to the supernatant.
In wt splenocytes an extracellular concentration of $0.08 \pm 0.029 \mu \mathrm{M}$ FTY720 and $0.144 \pm 0.087 \mu \mathrm{M}$ FTY720-P was determined (Figure 2A). However, in contrast, we assessed a dramatic intracellular increase over the supernatant concentration. For FTY720 $(87.037 \pm 52.579 \mu \mathrm{M})$ a 1088 -fold and for FTY720-P $(49.796 \pm 27.572 \mu \mathrm{M})$ a 346-fold elevation was evaluated. For the SphK1-deficient spleen cells, amounts of $0.064 \pm 0.009 \mu \mathrm{M}$ FTY720 and 0.176 $\pm 0.019 \mu \mathrm{M}$ FTY720-P were calculated in the supernatant (Figure 2B). Conversely, the intracellular concentrations of FTY720 and FTY720-P in SphK1-deficient cells were $111.441 \pm 16.663 \mu \mathrm{M}$ and 75.262 $\pm 4.965 \mu \mathrm{M}$, implying a 1741- and 428-fold

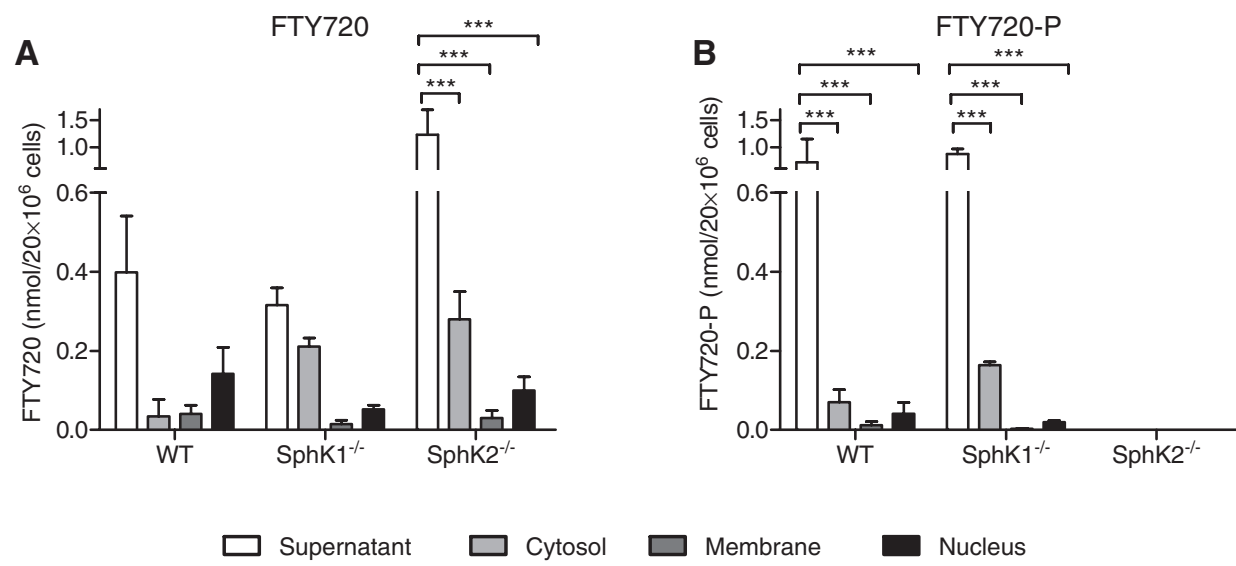

Figure 1 Comparison of FTY720 and FTY720-P amount in different cellular compartments of murine splenocytes. $20 \times 10^{6}$ splenocytes from wt-C57BL/6, SphK1- and SphK2-deficient mice were incubated for $15 \mathrm{~h}$ with $1 \mu \mathrm{M}$ FTY720 and the concentrations of FTY720 (A) and FTY720-P (B) were obtained by LC-MS/MS and calculated in nmol on a linear scale. Data are given as mean \pm SD from $n=6$ and significant values are indicated as $p<0.001$ achieved by two-way ANOVA statistical calculations. 

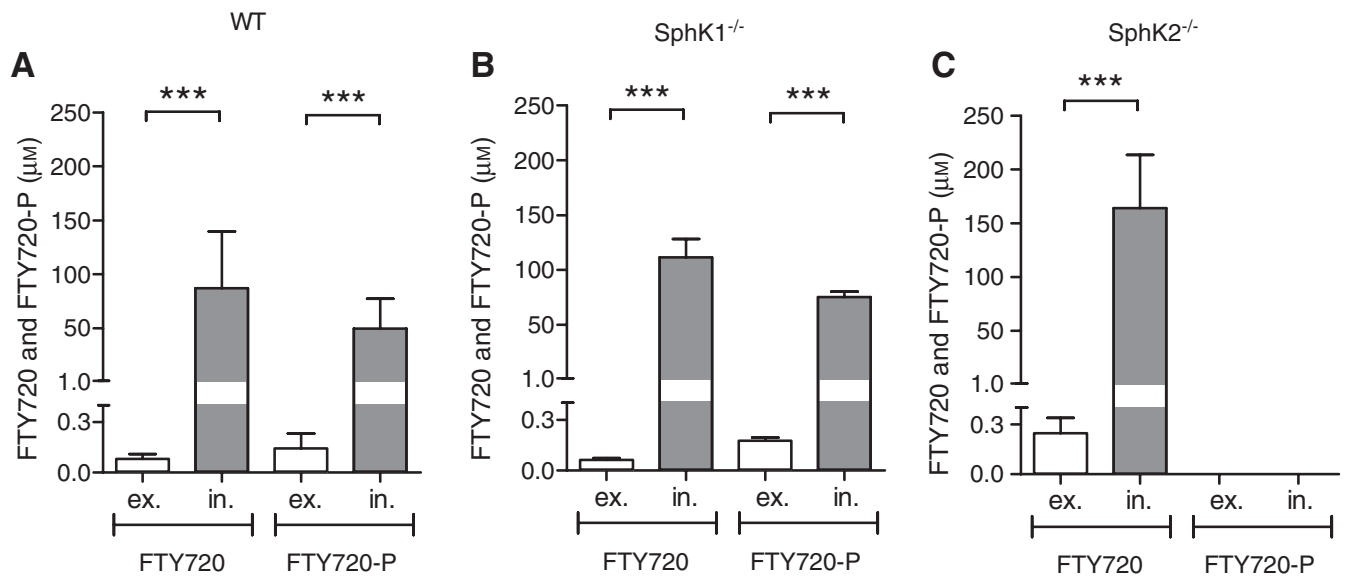

Figure 2 Extracellular vs. intracellular molar concentrations of FTY720 and FTY720-P of murine splenocytes in original cell volumes. From the calculated amounts of FTY720 and FTY720-P of wt-C57BL/6 (A), SphK1- (B) and SphK2- (C) deficient spleen cells measured by LC-MS/MS were assessed the total intracellular (in.) and extracellular (ex.) concentrations in $\mu \mathrm{M}$, taking the original natural cell volume, the dilution factor and the extraction volume into account. Data are given as mean \pm SD from $n=6$ and significant values are indicated as $p<0.001$ achieved by two-way ANOVA statistical calculations.

accumulation inside the cells. As mentioned above, the SphK2-deficient splenocytes were not able to phosphorylate FTY720. Hence, there is a greater intracellular accumulation of FTY720 (164.059 \pm 49.6 FTY720 $\mu \mathrm{M})$, which was 664-times over the supernatant fraction concentration $(0.247 \pm 0.092 \mu \mathrm{M})$ but no detectable amounts of FTY720-P where found (Figure $2 \mathrm{C}$ ).

\section{Discussion}

Our newly established LC-MS/MS method for analyzing FTY720 and FTY720-P (Ferreirós et al., 2012) allowed us to determine the distribution of FTY720 and FTY720-P in murine splenocytes. We distinguished four fractions: (1) medium surrounding the cells, (2) cytosol, (3) nucleus and (4) the membranous compartments. Because the major FTY720 bio-activating enzyme SphK2 is located primarily in the nuclear and membranous compartments (Igarashi et al., 2003; Hait et al., 2009) we were interested to analyze how FTY720 and FTY720-P are distributed not only in wild type mice, but also in the splenocytes deficient for SphK2. Furthermore, our concern was to determine whether the distribution of FTY720 and FTY720-P is affected in the absence of the enzyme SphK1, phosphorylating S1P extranuclearly.

The present study focuses on a representative mixture of immune cells that is typically involved in autoimmune diseases and demonstrated a dramatic intracellular molar accumulation of FTY720 and FTY720-P (Figure 2). This accumulation was calculated in detail, considering the molarities and the distribution volumes in different compartments, e.g. of the supernatant $(5 \mathrm{ml})$ vs. the splenocytes with a volume of $3.6 \mu \mathrm{l}$ for $20 \times 10^{6}$ cells. Thus, our data imply a prominent intracellular increase of FTY720/ FTY720-P in wild type and SphK1-deficient spleen cells of 346- to 1741-fold, respectively. In comparison, the highest concentration of S1P measured in vivo was only about 1 $\mu \mathrm{M}$ in the extracellular blood compartment (Skoura and Hla, 2009). Our results are strongly supported by the findings of Sensken et al. (2009) who also demonstrated an accumulation of FTY720 in lymphocytes. Our data confirm these findings and moreover, show the intracellular distribution of Fingolimod in different compartments of the spleen cells and the influence of S1P metabolizing enzymes.

Clearly, FTY720 is uniquely phosphorylated by SphK2 as confirmed in this study (Table 1C, Figures 1 and 2) and described before by Paugh et al. (2003). Furthermore, data normalized to the suspension volume and to molecular weight of the respective drug revealed that FTY720 was localized apart from a big proportion within the supernatant, mainly in the nucleus of wild type splenocytes (Figure 1A). However, in SphK1- and SphK2-deficient splenocytes the highest intracellular levels of FTY720 were not detected in the nucleus but in the cytosol. Obviously the deficiency of one of the two S1P-generating enzymes is responsible for this differential distribution, although up to now only SphK2 has been assigned to interact with FTY720, performing the phosphorylation. Additionally, in SphK2-deficient cells, the total amount of FTY720 measured was dramatically increased compared to wild type cells because the cells were unable to synthesize any 
FTY720-P. These increased concentrations of FTY720 might also contribute to the differential distribution of the compound detected in each of the four fractions (Figure 1). It is known from the literature that a deficiency of both sphingosine kinases, leads to embryonic lethality. However, no obvious phenotype is known in single knockout mice, indicating that apart from specific exceptions (Oskeritzian et al., 2008; Price et al., 2013) one enzyme may substitute the other (Alemany et al., 2007). The increased concentration of FTY720-P in the cytosol of the SphK1-deficient cells may thus be the result of a compensatory increase of SphK2 activity.

Intracellular, endogenous lipids undergo a continuous turnover with an exchange rate of at least $1 \mu \mathrm{m}^{2}$ of lipid layer in a few seconds (van Meer and de Kroon, 2011). Nevertheless, lipids like sterols or sphingolipids reside at distinct intracellular spaces and are not spread randomly throughout the double-layered membranes of the cell. Gerrit van Meer and colleagues postulated that specific lipid sorting takes place due to a vesicular pathway maintained by the Golgi apparatus (Simons and van Meer, 1988; Neumann and van Meer, 2008). For the endogenous sphingolipid S1P this transportation system, and also the export via ABC transporters (Liu et al., 2014; Nishi et al., 2014) and the SPNS2 transporters (Hisano et al., 2011; Fukuhara et al., 2012), have been repeatedly described. With regard to FTY720, there exist only a few inconclusive studies investigating its transportation mechanisms. In T cells, both FTY720 and FTY720$P$ enhanced the efflux activity of the ABCB1 transporter (Honig et al., 2003). In contrast, stimulus-mediated release of FTY720-P has been described to be independent of ABCB1 or ABCC1 in platelets (Anada et al., 2007). Another study reasoned that FTY720-P is transported out of mouse brain and spinal cord endothelial cells by ABCC1 (Mrp1) (Cartwright et al., 2013). Furthermore, FTY720 was implemented to affect the cholesterol balance and increased the ABCA1 mRNA and protein levels in human primary macrophages (Blom et al., 2010). While these conflicting data are not yet resolved experimentally, the most likely explanation is a cell typeand tissue-specific expression and regulation of sphingolipid transport systems. Besides transportation, lipid levels are also regulated by their metabolism.

Intracellular S1P is faced continuously towards its degrading enzymes, the S1P phosphatases $1 / 2$ as well as S1P lyase. However, according to published evidence, the S1P lyase is not capable to cleave FTY720-P but is rather inhibited by the compound (Bandhuvula et al., 2005). This represents another plausible explanation for a constantly high intracellular Fingolimod concentration in respective sub-compartments. Lim et al. (2011) determined a $K_{m}$ value for SphK2 to phosphorylate FTY720 of about 5-10 $\mu \mathrm{m}$. Therefore, it seems quite reasonable to assume that these high concentrations of FTY720$\mathrm{P}$ are also reached in humans receiving Fingolimod for the treatment of MS. Otherwise the required levels of the phosphorylated Fingolimod compound would not be available for the S1P receptor targets. As mentioned above, to achieve a therapeutic sequestration effect in disease such as relapsing-remitting MS, it is crucial for FTY720-P to bind to the S1PRs and to abolish the migration of autoreactive $\mathrm{T}$ cells to the blood. It is however very possible that the significant intracellular accumulation of this substance described by our data, may explain part of the surprising therapeutic efficacy of even low dosage levels in MS as compared to its formerly applied dosage in transplantation (Kappos et al., 2010). Therefore, by interpreting our findings in a positive direction, Fingolimod may affect immune cell-relevant intracellular targets, such as phospholipase A2 (PLA2) and protein phosphatase 2A (PP2A) (Payne et al., 2007; Saddoughi et al., 2013; Arlt et al., 2014). These results have to be further confirmed by an in vivo model, e.g. by intra peritoneal or oral treatment of mice with FTY720, isolating spleen cells followed by detection of the two compounds via LC-MS/MS. Thus, above the S1P receptor-dependent activities of Fingolimod, the prominent intracellular accumulation of FTY720 shown in our investigation may point to additional and relevant molecular targets not considered in MS treatment so far. Therefore, these findings should be discussed for both, optimization of the therapeutic application including a thorough drug monitoring in order to avoid unwanted side effects and the evaluation of new intracellular drug targets being supportive during a long-term treatment of patients with autoimmune diseases.

\section{Materials and methods}

\section{Materials}

Acetonitrile, ethanol and methanol (gradient grade), tetrahydrofuran (for HPLC), formic acid (89-91\% purity grade) and hydrochloric acid (32\% purity grade), both for analysis, were purchased from Merck (Darmstadt, Germany). Water (LC-MS grade) and dimethyl sulfoxide (analytical reagent grade) were obtained from Carl Roth (Karlsruhe, Germany) and Fisher Scientific (Schwerte, Germany), respectively.

FTY720 (MW: $307.47 \mathrm{~g} / \mathrm{mol}$ ) and FTY720-P (MW: $387.5 \mathrm{~g} / \mathrm{mol}$ ) were purchased from Cayman Chemical (Ann Arbor, MI, USA) as well as C17-sphingosine (C17-SPH) and C17-sphingosine-1-phosphate (C17-S1P) which were used as internal standards. 


\section{Preparation of splenocytes and fractionation}

Female wild type mice (wt-C57BL/6) were purchased from Harlan Winkelmann (Borchen, Germany); Female SphK1-deficient (SphK ${ }^{/}$) and SphK2-deficient (SphK2 ${ }^{-/}$) mice, backcrossed to the $\mathrm{C} 57 \mathrm{BL} / 6$ background, were bred at the local animal facility under specific pathogen-free conditions (Frankfurt, Germany). Whole spleens were dissected from mice, gently homogenized with a glass tissue homogenizer (OMNI International, USA), and following ammoniumchloride-potassium (ACK) buffer mediated erythrolysis cultured in Iscove's medium supplemented with 5\% fetal calf serum (FCS) (PAA Laboratories, Egelsbach, Germany), 2 mM L-glutamine, $100 \mathrm{IU} / \mathrm{ml}$ penicillin, $100 \mu \mathrm{g} / \mathrm{ml}$ streptomycin, $1 \mathrm{~mm}$ sodium pyruvate, $100 \mu \mathrm{M}$ non-essential amino acids and $50 \mu \mathrm{m} \beta$-mercaptoethanol (all from Sigma Aldrich, Deisenhofen, Germany) in an humidified incubator $\left(5 \% \mathrm{CO}_{2}\right.$ and $\left.37^{\circ} \mathrm{C}\right)$.

Splenocytes were seeded at $20 \times 10^{6}$ cells $/ 5 \mathrm{ml}$ in T25 cell culture flasks (Sigma Aldrich, Deisenhofen, Germany) with serum-free Iscove's medium (PAA Laboratories, Egelsbach, Germany). The cells were incubated with $1 \mu \mathrm{M}$ FTY720 (Cayman Chemical, Ann Arbor, MI, USA) for $15 \mathrm{~h}$. The splenocytes were then gently rubber-scraped and centrifuged at $4^{\circ} \mathrm{C}$ at $300 \mathrm{~g}$. The cell-free supernatants were collected (medium samples). The remaining cell pellets were lysed with a sonicator (Branson Sonifier 450, Heinemann Labortechnik, Schwäbisch Gmünd, Germany) (30 s, 50 W, 10\%) in $500 \mu$ l proteinase inhibitor buffer (PI) (Roche, Basel, Switzerland) and 10 mM HEPES (Sigma Aldrich, Deisenhofen, Germany). Subsequent centrifugation at $400 \mathrm{~g}$ for $10 \mathrm{~min}$ at $4^{\circ} \mathrm{C}$ yielded the nuclear fraction as pellet while the supernatant was re-centrifuged at $180000 \mathrm{~g}$ (TLX ultracentrifuge, Beckman, Ramsey, USA) for 30 min providing the membrane fraction and the cytosolic fraction. The nuclear pellets as well as the membrane fractions were resuspended in PI-buffer and diluted 1:10 before lipid extraction to be inside the lower and upper limit of quantification for the LC-MS/MS detection process.

\section{Sample extraction and standard preparation}

The generated samples were extracted as we have previously described (Ferreirós et al., 2012). Briefly, the sample was spiked with the internal standard solved in methanol $(15 \mathrm{ng} / \mathrm{ml} \mathrm{C17-sphingosine} \mathrm{and} 10$ $\mathrm{ng} / \mathrm{ml}$ C17-sphingosine-1-phosphate). For the preparation of a standard curve for FTY720 and FTY720-P appropriate methanolic working solutions were generated $(1 \mathrm{mg} / \mathrm{ml}$ in methanol). A calibration curve from $0.875-175 \mathrm{ng} / \mathrm{ml}$ for FTY720 and from 2-400 ng/ml for FTY720$\mathrm{P}$ was prepared by spiking of the appropriate methanolic working solution. Then, deionized water, methanol and the extraction solvent (chloroform:methanol:HCl, v/v/v, 83:15:2) were added. After vortexing this mixture for $1 \mathrm{~min}$ and a subsequent centrifugation at $17000 \mathrm{~g}$, the upper layer was disposed and the organic layer was evaporated at $45^{\circ} \mathrm{C}$ under a nitrogen stream. The residue was reconstituted in $50 \mu \mathrm{l}$ methanol and used for injection into the LC-MS/MS system.

\section{LC-MS/MS measurement}

FTY720 and FTY720-P were quantified with LC-MS/MS as described by us before (Ferreirós et al., 2012). Briefly, $10 \mu \mathrm{l}$ of the samples were injected into the LC-MS/MS system with a flow rate of $0.3 \mathrm{ml} / \mathrm{min}$ and separated chromatographically, using a Luna C18 (2) column $(150 \times 2 \mathrm{~mm}$ I.D., $5 \mu \mathrm{m}$ particle size and $100 \AA$ pore size $)$ with a C18 guard column $(4 \times 2 \mathrm{~mm}$ I.D.) (Phenomenex, Aschaffenburg, Germany). The LC-MS/MS system consisted of an Agilent 1100 Series binary pump (G1312A) and degasser (G1379A) (Waldbronn, Germany) with an HTC PAL autosampler (Chromtech, Idstein, Germany). A triple quadrupole mass spectrometer 4000 QTRAP equipped with a Turbo V IonSpray source operated in positive ESI mode was used for detection (AB Sciex, Darmstadt, Germany).

\section{Statistical analysis}

The software package of Graph Pad Prism 5.01 (La Jolla, USA) for Windows was used for statistical analysis of collected and presented data. Data are given as mean \pm SD from six independent experiments. Appropriate two-way ANOVA as the statistical calculation method was applied and significant values are indicated as asterisks in

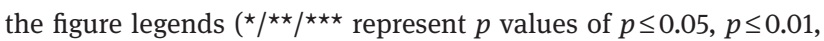
$p \leq 0.001$, respectively).

Acknowledgments: We would like to thank J. Textor, University of Lübeck, for his helpful advice regarding speciesspecific details of lymphocyte sizes and volumes. This work was supported by grants from the Sonderforschungsbereich 1039, Deutsche Forschungsgemeinschaft (Graduate school GRK1172 and FOG784), Merck KGaA, LOEWE Lipid Signaling Center LiFF and the Swiss National Science Foundation.

\section{References}

Alemany, R., van Koppen, C.J., Danneberg, K., Ter Braak, M., and Meyer Zu Heringdorf, D. (2007). Regulation and functional roles of sphingosine kinases. Naunyn Schmiedebergs Arch. Pharmacol. 374, 413-428.

Anada, Y., Igarashi, Y., and Kihara, A. (2007). The immunomodulator FTY720 is phosphorylated and released from platelets. Eur. J. Pharmacol. 568, 106-111.

Arlt, O., Schwiebs, A., Japtok, L., Ruger, K., Katzy, E., Kleuser, B., and Radeke, H.H. (2014). Sphingosine-1-phosphate modulates dendritic cell function: focus on non-migratory effects in vitro and in vivo. Cell. Physiol. Biochem. 34, 27-44.

Bandhuvula, P., Tam, Y.Y., Oskouian, B., and Saba, J.D. (2005). The immune modulator FTY720 inhibits sphingosine-1-phosphate lyase activity. J. Biol. Chem. 280, 33697-33700.

Blaho, V.A. and Hla, T. (2014). An update on the biology of sphingosine 1-phosphate receptors. J. Lipid Res. 55, 1596-1608.

Blom, T., Back, N., Mutka, A.L., Bittman, R., Li, Z., de Lera, A., Kovanen, P.T., Diczfalusy, U., and Ikonen, E. (2010). FTY720 stimulates 27-hydroxycholesterol production and confers atheroprotective effects in human primary macrophages. Circ. Res. 106, 720-729.

Brinkmann, V., Billich, A., Baumruker, T., Heining, P., Schmouder, R., Francis, G., Aradhye, S., and Burtin, P. (2010). Fingolimod 
(FTY720): discovery and development of an oral drug to treat multiple sclerosis. Nat. Rev. Drug Discov. 9, 883-897.

Bryan, L., Kordula, T., Spiegel, S., and Milstien, S. (2008). Regulation and functions of sphingosine kinases in the brain. Biochim. Biophys. Acta 1781, 459-466.

Cartwright, T.A., Campos, C.R., Cannon, R.E., and Miller, D.S. (2013). Mrp1 is essential for sphingolipid signaling to p-glycoprotein in mouse blood-brain and blood-spinal cord barriers. J. Cereb. Blood Flow Metab. 33, 381-388.

Cinamon, G., Zachariah, M.A., Lam, O.M., Foss, F.W., and Cyster, J.G. (2008). Follicular shuttling of marginal zone B cells facilitates antigen transport. Nat. Immunol. 9, 54-62.

Ferreirós, N., Labocha, S., Schröder, M., Radeke, H.H., and Geisslinger, G. (2012). LC-MS/MS determination of FTY720 and FTY720-phosphate in murine intracellular compartments and human plasma. J. Chromatogr. B Analyt. Technol. Biomed. Life. Sci. 887-888, 122-127.

Fukuhara, S., Simmons, S., Kawamura, S., Inoue, A., Orba, Y., Tokudome, T., Sunden, Y., Arai, Y., Moriwaki, K., Ishida, J., et al. (2012). The sphingosine-1-phosphate transporter Spns2 expressed on endothelial cells regulates lymphocyte trafficking in mice. J. Clin. Invest. 122, 1416-1426.

Hait, N.C., Allegood, J., Maceyka, M., Strub, G.M., Harikumar, K.B., Singh, S.K., Luo, C., Marmorstein, R., Kordula, T., Milstien, S. et al. (2009). Regulation of histone acetylation in the nucleus by sphingosine-1-phosphate. Science 325, 1254-1257.

Hisano, Y., Kobayashi, N., Kawahara, A., Yamaguchi, A., and Nishi, T. (2011). The sphingosine 1-phosphate transporter, SPNS2, functions as a transporter of the phosphorylated form of the immunomodulating agent FTY720. J. Biol. Chem. 286, 1758-1766.

Honig, S.M., Fu, S., Mao, X., Yopp, A., Gunn, M.D., Randolph, G.J., and Bromberg, J.S. (2003). FTY720 stimulates multidrug transporter- and cysteinyl leukotriene-dependent T cell chemotaxis to lymph nodes. J. Clin. Invest. 111, 627-637.

Huwiler, A. and Pfeilschifter, J. (2008). New players on the center stage: sphingosine 1-phosphate and its receptors as drug targets. Biochem. Pharmacol. 75, 1893-1900.

Igarashi, N., Okada, T., Hayashi, S., Fujita, T., Jahangeer, S., and Nakamura, S. (2003). Sphingosine kinase 2 is a nuclear protein and inhibits DNA synthesis. J. Biol. Chem. 278, 46832-46839.

Kappos, L., Radue, E.W., O'Connor, P., Polman, C., Hohlfeld, R., Calabresi, P., Selmaj, K., Agoropoulou, C., Leyk, M., ZhangAuberson, L., et al. (2010). A placebo-controlled trial of oral fingolimod in relapsing multiple sclerosis. N. Engl. J. Med. 362, 387-401.

Lim, K.G., Sun, C., Bittman, R., Pyne, N.J., and Pyne, S. (2011). (R)FTY720 methyl ether is a specific sphingosine kinase 2 inhibitor: effect on sphingosine kinase 2 expression in HEK 293 cells and actin rearrangement and survival of MCF-7 breast cancer cells. Cell. Signal. 23, 1590-1595.

Limaye, V. (2008). The role of sphingosine kinase and sphingosine1-phosphate in the regulation of endothelial cell biology. Endothelium 15, 101-112.

Liu, M., Seo, J., Allegood, J., Bi, X., Zhu, X., Boudyguina, E., Gebre, A.K., Avni, D., Shah, D., Sorci-Thomas, M.G. et al. (2014). Hepatic apolipoprotein M (ApoM) overexpression stimulates formation of larger ApoM/sphingosine 1-phosphate-enriched plasma high density lipoprotein. J. Biol. Chem. 289, 2801-2814.

Mandala, S., Hajdu, R., Bergstrom, J., Quackenbush, E., Xie, J., Milligan, J., Thornton, R., Shei, G.J., Card, D., Keohane, C., et al.
(2002). Alteration of lymphocyte trafficking by sphingosine1-phosphate receptor agonists. Science 296, 346-349.

Matloubian, M., Lo, C.G., Cinamon, G., Lesneski, M.J., Xu, Y., Brinkmann, V., Allende, M.L., Proia, R.L., and Cyster, J.G. (2004). Lymphocyte egress from thymus and peripheral lymphoid organs is dependent on S1P receptor 1 . Nature 427 , 355-360.

Moriue, T., Igarashi, J., Yoneda, K., Nakai, K., Kosaka, H. and Kubota, Y. (2008). Sphingosine 1-phosphate attenuates $\mathrm{H}_{2} \mathrm{O}_{2}$ induced apoptosis in endothelial cells. Biochem. Biophys. Res. Commun. 368, 852-857.

Neumann, S. and van Meer, G. (2008). Sphingolipid management by an orchestra of lipid transfer proteins. Biol. Chem. 389, 1349-1360.

Nishi, T., Kobayashi, N., Hisano, Y., Kawahara, A. and Yamaguchi, A. (2014). Molecular and physiological functions of sphingosine 1-phosphate transporters. Biochim. Biophys. Acta 1841, 759-765.

Oo, M.L., Chang, S.H., Thangada, S., Wu, M.T., Rezaul, K., Blaho, V., Hwang, S.I., Han, D.K., and Hla, T. (2011). Engagement of S1P(1)-degradative mechanisms leads to vascular leak in mice. J. Clin. Invest. 121, 2290-2300.

Oskeritzian, C.A., Alvarez, S.E., Hait, N.C., Price, M.M., Milstien, S., and Spiegel, S. (2008). Distinct roles of sphingosine kinases 1 and 2 in human mast-cell functions. Blood 111, 4193-4200.

Paugh, S.W., Payne, S.G., Barbour, S.E., Milstien, S., and Spiegel, S. (2003). The immunosuppressant FTY720 is phosphorylated by sphingosine kinase type 2. FEBS Lett. 554, 189-193.

Payne, S.G., Oskeritzian, C.A., Griffiths, R., Subramanian, P., Barbour, S.E., Chalfant, C.E., Milstien, S., and Spiegel, S. (2007). The immunosuppressant drug FTY720 inhibits cytosolic phospholipase A2 independently of sphingosine-1-phosphate receptors. Blood 109, 1077-1085.

Price, M.M., Oskeritzian, C.A., Falanga, Y.T., Harikumar, K.B., Allegood, J.C., Alvarez, S.E., Conrad, D., Ryan, J.J., Milstien, S., and Spiegel, S. (2013). A specific sphingosine kinase 1 inhibitor attenuates airway hyperresponsiveness and inflammation in a mast cell-dependent murine model of allergic asthma. J. Allergy Clin. Immunol. 131, 501-511. e501.

Qin, J., E. Berdyshev, Goya, J., Natarajan, V., and Dawson, G. (2010). Neurons and oligodendrocytes recycle sphingosine 1-phosphate to ceramide: significance for apoptosis and multiple sclerosis. J. Biol. Chem. 285, 14134-14143.

Rathmell, J.C., Farkash, E.A., Gao, W., and Thompson, C.B. (2001). IL-7 enhances the survival and maintains the size of naive $T$ cells. J Immunol 167, 6869-6876.

Saddoughi, S.A., Song, P., and Ogretmen, B. (2008). Roles of bioactive sphingolipids in cancer biology and therapeutics. Subcell. Biochem. 49, 413-440.

Saddoughi, S.A., Gencer, S., Peterson, Y.K., Ward, K.E., Mukhopadhyay, A., Oaks, J., Bielawski, J., Szulc, Z.M., Thomas, R.J., Selvam, S.P., et al. (2013). Sphingosine analogue drug FTY720 targets I2PP2A/SET and mediates lung tumour suppression via activation of PP2A-RIPK1-dependent necroptosis. EMBO Mol. Med. 5, 105-121.

Schwab, S.R., Pereira, J.P., Matloubian, M., Xu, Y., Huang, Y., and Cyster, J.G. (2005). Lymphocyte sequestration through S1P lyase inhibition and disruption of S1P gradients. Science 309, 1735-1739. 
Sensken, S.C., Bode, C., and Graler, M.H. (2009). Accumulation of fingolimod (FTY720) in lymphoid tissues contributes to prolonged efficacy. J. Pharmacol. Exp. Ther. 328, 963-969.

Simons, K. and van Meer, G. (1988). Lipid sorting in epithelial cells. Biochemistry 27, 6197-6202.

Skoura, A. and Hla, T. (2009). Lysophospholipid receptors in vertebrate development, physiology, and pathology. J. Lipid Res. 50 (Suppl.), S293-298.
Spiegel, S. and Milstien, S. (2011). The outs and the ins of sphingosine-1-phosphate in immunity. Nat. Rev. Immunol. 11, 403-415.

van Meer, G. and de Kroon, A.I. (2011). Lipid map of the mammalian cell. J. Cell Sci. 124, 5-8.

von Andrian, U.H. and Mackay, C.R. (2000). T-cell function and migration. Two sides of the same coin. N. Engl. J. Med 343, 1020-1034. 